\title{
Overexpression of TNFa induces senescence, autophagy and mitochondrial dysfunctions in melanoma cells
}

\author{
Silvia Tyciakova ${ }^{1 *}$ (D), Valeria Valova ${ }^{1,2}$, Barbora Svitkova $^{1}$ and Miroslava Matuskova ${ }^{1}$
}

\begin{abstract}
Background: Tumor necrosis factor alpha (TNFa) is a pleiotropic cytokine with both anti-tumorigenic and protumorigenic activity, affecting tumor cell biology, the balance between cell survival and death. The final effect of TNFa is dependent on the type of malignant cells, with the potential to arrest cancer progression.

Methods: In order to explain the diverse cellular response to TNFa, we engineered melanoma and colorectal carcinoma cell lines stably overexpressing this cytokine.

Results: Under the TNFa overexpression, significant upregulation of two genes was observed: proinflammatory cytokine IL6 gene in melanoma cells A375 and gene for pro-apoptotic ligand TRAIL in colorectal carcinoma cells HT29, both mediated by TNFa/TNFR1 signaling. Malignant melanoma line A375 displayed also increased autophagy on day 3, followed by premature senescence on day 6. Both processes seem to be interconnected, following earlier apoptosis induction and deregulation of mitochondrial functions. We documented altered mitochondrial status, lowered ATP production, lowered mitochondrial mass, and changes in mitochondrial morphology (shortened and condensed mitochondria) both in melanoma and colorectal carcinoma cells. Overexpression of TNFa was not linked with significant affection of the subpopulation of cancer stem-like cells in vitro. However, we could demonstrate a decrease in aldehyde dehydrogenase (ALDH) activity up to 50\%, which is associated with to the stemness phenotype.

Conclusions: Our in vitro study of direct TNFa influence demonstrates two distinct outcomes in tumor cells of different origin, in non-epithelial malignant melanoma cells of neural crest origin, and in colorectal carcinoma cells derived from the epithelium.
\end{abstract}

Keywords: TNFa, Melanoma, Senescence, Autophagy, Aldehyde dehydrogenase activity, Mitochondrial status, Cancer stem cell-related markers

\footnotetext{
* Correspondence: silvia.tyciakova@savba.sk

${ }^{1}$ Cancer Research Institute, Biomedical Research Center of Slovak Academy of Sciences, Dubravska cesta 9, 84505 Bratislava, Slovakia

Full list of author information is available at the end of the article
}

(c) The Author(s). 2021 Open Access This article is licensed under a Creative Commons Attribution 4.0 International License, which permits use, sharing, adaptation, distribution and reproduction in any medium or format, as long as you give appropriate credit to the original author(s) and the source, provide a link to the Creative Commons licence, and indicate if changes were made. The images or other third party material in this article are included in the article's Creative Commons licence, unless indicated otherwise in a credit line to the material. If material is not included in the article's Creative Commons licence and your intended use is not permitted by statutory regulation or exceeds the permitted use, you will need to obtain permission directly from the copyright holder. To view a copy of this licence, visit http://creativecommons.org/licenses/by/4.0/ The Creative Commons Public Domain Dedication waiver (http://creativecommons.org/publicdomain/zero/1.0/) applies to the data made available in this article, unless otherwise stated in a credit line to the data. 


\section{Background}

Tumor necrosis factor $\alpha$ (TNF $\alpha)$, a key inflammatory cytokine, can drive both tumor elimination and promotion in cancer patients, depending on the dose and cancer type [1-3]. Overexpression of TNF $\alpha$ in engineered tumor cells (myeloma, fibrosarcoma, breast carcinoma) blocks their engraftment and growth in mice and creates a tumor suppressive microenvironment [4-7]. The effect of TNF $\alpha$ is pleiotropic, modulating the tumor microenvironment via paracrine mechanisms in the context of the cancer tissue. Despite possible positive antitumor effects, the use of this cytokine for therapeutic applications in humans is very limited. TNF $\alpha$ was used as a 'pre-activator' of human mesenchymal stromal cells (MSCs), which were stimulated to produce pro-apoptotic ligand TRAIL and reduced growth of experimental metastases [8]. Engineered MSC overexpressing $T N F \alpha$, coinjected with malignant melanoma cells, reduced growth of subcutaneous xenografts. Such engineered TNF $\alpha$-MSC kept the TNF $\alpha$ production for more than 3 months and lost their significant tumor supportive potential [9]. But they had no inhibitory potential on induced experimental melanoma lung metastases after systemic administration [10].

The subpopulation of cancer stem-like cells (CSCs) is believed to be responsible for the relapse of cancer disease and is able to initiate tumor growth and metastases $[11,12]$. CSCs are identified as the population of tumor cells positive for the unique composition of CSCs markers (CD133, CD44, CD166, ALDH positivity, and others, depending on cancer type). TNF $\alpha$ can affect CSCs subpopulation in vitro and enhances CSCs-like phenotype of oral squamous cell carcinoma [13] and pancreatic cancer cells [14]. Inflammatory factors can promote breast CSCs via canonical NF- $\mathrm{BB} / \mathrm{HIF} 1 \alpha$ signaling, enhanced by p53 inactivation [15] or via the noncanonical NF-kB pathway [16]. Long-term treatment of breast cancer cell line with a combination of TNF $\alpha$ and TGF $\beta$ induced epithelial-mesenchymal transition, mammosphere formation, and extreme overexpression of genes associated with stemness [17].

Between senescence and autophagy (both considered as possible hallmarks of cancer) [18] is a strong relationship and both are usually started in stress conditions, such as oxidative stress, DNA damage, mitochondrial damage and oncogene activation. Studies suggest that autophagy promotes senescence, while other reports show that mechanism of autophagy can be anti-senescent [19]. Autophagy is usually cytoprotective, maintaining healthy cells, preventing tissue damage, and cancer initiation. After suppression of the autophagy, an increase of cancer-related inflammation was observed. On the other hand, autophagy enhances stress tolerance and fulfils the high nutrient demands of cancer cells (reviewed in $[20,21]$ ). Senescence is also a tumor-suppressive mechanism, eliminating potentially dangerous mutated cells and providing a barrier against tumorigenesis. Premature senescence is one of the outcomes of chemo- and radiotherapy in cancer treatment. Senescent cells in situ affect their microenvironment by secretion of chemokines, pro-inflammatory cytokines, and proteases, creating senescence-related secretory phenotype (SASP) (reviewed in [19, 22]). All processes initiated by TNF $\alpha$ are under the dominant control of ubiquitously expressed receptor TNFR1, although receptor TNFR2 may contribute to these changes as well. TNF $\alpha$ triggers both autophagy and pro-survival NF- $\kappa B$ signaling via receptor TNFR1 [23]. TNF $\alpha$ is directly involved in the generation of reactive oxygen species. Because TNF $\alpha$ is affecting mitochondrial ATP production and homeostasis, it is manifested as a mild uncoupler of the respiratory chain $[24,25]$. In recent years, mitochondria of cancer cells are discussed as new possible targets for antitumor therapy, and the relationship between high mitochondrial mass and stemness phenotype is intensively studied [26, 27].

In order to study the direct effects of TNF $\alpha$ on tumor cell biology, we engineered cells of two different origins continually overexpressing human $T N F \alpha$ gene: epithelial colorectal adenocarcinoma lines HT29, HCT116, and malignant melanoma lines A375 and M4Beu of neural crest origin. We examined the subpopulation of CSCs, including the ALDH enzyme activity. We also aimed to show the interconnection of apoptosis, changes in mitochondrial status, autophagy and senescence accompanied by changes of mRNA expression profile.

\section{Methods}

\section{Cell lines and chemicals}

Human melanoma cell lines A375 (ECACC 88113005), M4Beu (kindly provided by Dr. J. Bizik, BMC SAS), human colorectal carcinoma cell lines HT29 (ECACC 91072201; authenticated by STR Profiling) and HCT116 (ATCC ${ }^{\circ}$ CCL$247^{\mathrm{m}}$; authenticated by STR Profiling) were maintained in high-glucose $(4.5 \mathrm{mg} / \mathrm{ml})$ Dulbecco's modified Eagle's medium (DMEM) or RPMI 1640 medium (Biochrom AG, Berlin, Germany). Media were supplemented with 5 or $10 \%$ fetal bovine serum (FBS) (Biochrom AG) and $2 \mathrm{mM}$ glutamine. Cells were treated with recombinant human TNFo protein (PeproTech, London, UK; $100 \mathrm{ng} / \mathrm{ml}$ ) for indicated time, or with zafirlukast (Sigma-Aldrich, St Louis, MO, USA; $100 \mu \mathrm{M}$ ) for $1 \mathrm{~h}$. Cells were maintained in a humidified atmosphere at $37{ }^{\circ} \mathrm{C}$ and $5 \% \mathrm{CO}_{2}$. Cell lines were regularly tested for mycoplasma contamination based on PCR.

All chemicals were purchased from Sigma-Aldrich if not stated otherwise.

\section{Retroviral transduction}

Target cells were transduced with Moloney Murine Leukaemia virus-derived replication-deficient retroviral particles 
ST40hTNFa bearing human TNF $\alpha$ transgene as described previously [9]. At the multiplicity of infection (MOI) of 5-10, transduction efficiency of $50-90 \%$ was achieved. Transduction with ST40hTNFa retrovirus was verified by PCR, reverse transcriptase quantitative PCR (RTqPCR), and ELISA (Human TNF $\alpha$ Mini ELISA Development Kit, PeproTech). Engineered cell lines were named as A375hTNFa, M4BeuhTNFa, HT29hTNFa, and HCT116hTNFa.

\section{Kinetic measurement of cell proliferation and caspase 3/7} activation

Octaplicates of $3.0 \times 10^{3}$ cells per well were seeded in 96-well plates. Cell proliferation, based on cell confluence analysis, was monitored for 6 days or until the control cells reached $100 \%$ confluency. For monitoring of apoptosis induction, the CellPlayer 96-Well Caspase 3/7 reagent (Essen BioScience, Welwyn Garden City, UK) was added to a final concentration of $5 \mu \mathrm{M}$. Phase contrast and fluorescent images were acquired every $3 \mathrm{~h}$ using the IncuCyte ZOOM Kinetic Imaging System (Essen BioScience) and four images were taken per well. Data were analyzed using IncuCyte ZOOM software. Apoptosis activation was evaluated by dividing the number of specific green fluorescent objects with activated caspase-3/7 by the percentage of the cell confluence, as described is [9]. Proliferation was expressed as mean value of cell confluence in $\% \pm$ SDs.

\section{Immunophenotyping}

For the evaluation of CSCs-like cell surface markers, the following fluorochrome-conjugated antibodies were used: CD24-PE, CD26-PE, CD44-PE/CD44-APC, CD133PE/CD133-APC, CD271-PE, EpCAM-PE (Miltenyi Biotec, Bergisch Gladbach, Germany), CD166-PE (ALCAM, Immunotech, France), and cMET-APC (R\&D Systems, Abingdon, UK). Dead cells were excluded from the analysis based on DAPI staining. Cells were analyzed by BD FACS Canto $^{\text {Th }}$ II flow cytometer (Beckton Dickinson, USA) equipped with FacsDiva program. FCS Express software was used for the evaluation.

\section{Spheroid formation assay}

For 3D cultivation of spheroids, cells were seeded at a density of $3.0 \times 10^{3}$ cells per well in ultra-low attachment 24-well plates (Corning, NY, USA). Spheroids were grown for 3-4days in DMEM/F12 medium supplemented with $50 \mathrm{ng} / \mathrm{ml}$ EGF (Miltenyi Biotec), $20 \mathrm{ng} / \mathrm{ml}$ FGF (Miltenyi Biotec), B27 supplement (diluted 1:100, Miltenyi Biotec) and $2 \mathrm{mM}$ GlutaMAX (Gibco, Thermo Fisher Scientific, Waltham, USA). Spheroids were passaged with TrypLE Reagent (Gibco) after 4 days of growth. Images were obtained using Zeiss Axiovert.A1 microscope equipped with an Axiocam 208 color camera and lengths of spheres were measured using ZEN 2 software (Zeiss, Germany).

\section{Monitoring of mitochondrial status, morphology, and intracellular ATP}

Mitochondrial mass in tumor cells was stained with fluorescent dye MitoTracker Deep Red FM (25 nM) (Invitrogen, Thermo Fisher Scientific, Waltham, USA; Cat. no. M22426) for $30 \mathrm{~min}$ at $37^{\circ} \mathrm{C}$. Mitochondrial activity/mitochondrial membrane potential was monitored with MitoTracker ${ }^{\circ}$ Orange CMTMRos $(250 \mathrm{nM})$ (Invitrogen, Cat. no. M7510) also for $30 \mathrm{~min}$ at $37^{\circ} \mathrm{C}$. Samples were prepared as triplicates of $2.5 \times 10^{5}$ cells and fluorescence was measured using BD FACSCanto ${ }^{\mathrm{m}}$ II flow cytometer (Beckton Dickinson); values are expressed as mean fluorescence intensities + SDs.

Intracellular ATP levels were measured with CellTiterGlo Luminescent Cell Viability Assay (Promega Corporation, Madison, WI, USA) on GloMax Discover Microplate Reader (Promega Corporation). Exponentially growing live cells were harvested and pentaplicates of $2.0 \times 10^{4}$ cells were seeded in 96-well plates and stained immediately. Values representing ATP levels were expressed as means of relative luminescent units + SDs.

Mitochondrial morphology was evaluated by fluorescence microscopy. Cells growing on microscopic slides were stained with MitoTracker ${ }^{\circ}$ Orange CMTMRos (100 $\mathrm{nM}$ ) for $30 \mathrm{~min}$ at $37^{\circ} \mathrm{C}$, washed, fixed with $4 \%$ paraformaldehyde in $\mathrm{PBS}$ for $15 \mathrm{~min}$ at room temperature, and permeabilized with $0.05 \%$ Triton-X100 in PBS for $15 \mathrm{~min}$. Nuclei were visualized by DAPI; images were analyzed by AxioImager.Z2, Metafer (Alogo, Ltd., Czech Republic) at magnification 630x and Isis upgrade software (Alogo, Ltd.).

\section{Monitoring of mitochondrial DNA content}

Genomic and mitochondrial DNA from cultured cells was isolated together by DNazol reagent (BioTeke Corporation, Beijing, China). Mitochondrial DNA content represented by mtDNA gene for $16 \mathrm{~S}$ rRNA was normalized to a single copy nuclear gene for $\beta 2$-microglobulin using quantitative real-time PCR according Venegas et al. [28].

\section{Evaluation of aldehyde dehydrogenase (ALDH) activity}

To determine the ALDH activity in tumor cell lines, ALDEFLUOR $^{\mathrm{Tm}}$ Kit (StemCell Technologies) was used according to the manufacturer's instructions. Dead cells were excluded from the analysis based on DAPI or 7AAD staining. Cells were analyzed by BD FACSCanto ${ }^{\text {Tw }}$ II flow cytometer (Beckton Dickinson) equipped with FacsDiva program. FCS Express software was used for the evaluation.

\section{Autophagy detection}

Triplicates of $1.5-3.0 \times 10^{3}$ of cells per well were seeded in 12-well plates, incubated for 3-4 days and 1 day prior 
to staining, fresh media containing $10 \%$ FBS were added to the cells. Autophagic vacuoles in live cells were stained with CYTO-ID ${ }^{\circ}$ Autophagy detection kit (Enzo Life Sciences, Farmingdale, USA) for $30 \mathrm{~min}$ according to the manufacturer's instructions. Green fluorescent CYTO-ID signal in autophagic cells was monitored by BD FACSCanto ${ }^{\text {Th }}$ II flow cytometer (Beckton Dickinson) or IncuCyte ZOOM Kinetic Imaging System (Essen BioScience); values represent mean fluorescent intensities + SDs.

\section{Senescence $\beta$-galactosidase staining}

Duplicates of $5-10 \times 10^{3}$ of cells per well were seeded in 6-well plates and incubated for 6-7 days. Recombinant human TNF $\alpha$ protein was added 24 or $48 \mathrm{~h}$ after seeding at concentration $100 \mathrm{ng} / \mathrm{ml}$. Cells were stained with Senescence $\beta$-Galactosidase Staining Kit (Cell Signaling Technology, Danvers, USA) for $24 \mathrm{~h}$ according to the manufacturer's instructions. Senescent cells containing blue precipitates were visualized by Zeiss Axiovert 40C microscope and ZEN 2 software (Zeiss, Germany).

\section{Analysis of gene expression}

Expression analysis of mRNA for genes listed in Table 1 was determined by reverse transcriptase quantitative PCR (RT-qPCR). Total RNA was isolated from $5 \times 10^{5}$ cells using the NucleoSpin RNA II kit (Macherey-Nagel, Dueren, Germany) and was depleted from genomic DNA by DNase treatment (DNase I, RNase-free; Thermo Fisher Scientific). Next, $2 \mu \mathrm{g}$ of total RNA was reverse transcribed using the SensiFAST cDNA Synthesis kit (Bioline, London, UK) in one reaction. RT-qPCR was performed in triplicates or tetraplicates in Brilliant III Ultra-Fast SYBR QPCR Master Mix (Agilent Technologies, Santa Clara, USA), $250 \mathrm{nM}$ concentration of primers, and $1 \mu \mathrm{l}$ template cDNA per one reaction. The protocol for RT-qPCR was started with the activation step at $95^{\circ} \mathrm{C}$ for $3 \mathrm{~min}$ and followed by 40 cycles of the denaturation step at $95^{\circ} \mathrm{C}$ for $15 \mathrm{sec}$ and annealing/ polymerization at $60^{\circ} \mathrm{C}$ for $15 \mathrm{sec}$ with plate read step at $75^{\circ} \mathrm{C}$. PCR was performed in Bio-Rad 96FX cycler (BioRad Laboratories, Hercules, USA) and analyzed with Bio-Rad CFX Manager software version 1.6 as normalized fold expression using the $2^{-\Delta \Delta \mathrm{Cq}}$ method. The gene for hypoxanthine phosphoribosyl transferase 1 (HPRT1) was used as a reference gene. Oligonucleotides were synthesized by Metabion, Int. (Planegg, Germany) (Table 1).

\section{Statistical analysis}

The results are expressed as the means + SDs (flow cytometry data, RTqPCR) or SEM (RTqPCR Fig. 6). Values were tested for normality and then compared using a two-tailed unpaired Student's t-test or nonparametric Mann-Whitney U test in GraphPad Prism program, version 6 (GraphPad Software Inc., San Diego, CA, USA); ${ }^{*} p<0.05,{ }^{* *} p<0.01,{ }^{* * * *} p<0.001$ and ${ }^{* * * * *} p<0.0001$ were considered statistically significant.

\section{Results}

Overexpression of TNFa has a mild cytotoxic effect on tumor cells in vitro and is limited by the availability of TNFR1 and TNFR2 receptors

In engineered melanoma cells (A375hTNFa, M4BeuhT NFa) and colorectal carcinoma cells (HT29hTNFa, HCT $116 \mathrm{hTNFa}$ ), stable retroviral transduction elevated the mRNA expression of TNF $\alpha$ transgene up to $130.000 \mathrm{x}$ (engineered cells with approx. Cq 14-16 vs. parental cells with Cq 30-33; RTqPCR, Fig. 1a). Naïve parental cell lines displayed low basal mRNA expression of the intrinsic $T N F \alpha$ gene. ELISA confirmed concentrations of $50-150 \mathrm{ng} / \mathrm{ml}$ of soluble TNF $\alpha$ protein secreted by engineered cells reaching confluence of $90-100 \%$ into the

Table 1 List of primers used for RT-qPCR

\begin{tabular}{|c|c|c|c|}
\hline Gene & Forward primer sequence $5^{\prime} \rightarrow 3^{\prime}$ & Reverse primer sequence $5^{\prime} \rightarrow 3^{\prime}$ & Amplicon length (bp) \\
\hline TNFaRT & CAGAGGGAAGAGTTCCCCAG & CCTTGGTCTGGTAGGAGACG & 325 \\
\hline TNFR1 & ACCAAGTGCCACAAAGGAAC & GTTTCTGAAGCGGTGAAGG & 105 \\
\hline TNFR2 & GCTCTGACCAGGTGGAAACTCAAG & GGATGAAGTCGTGTTGGAGAACG & 224 \\
\hline TRAIL & ACCAACGAGCTGAAGCAGAT & ACGGAGTTGCCACTTGACTT & 141 \\
\hline $1 / 6$ & AAAGAGGCACTGGCAGAAAA & TITCACCAGGCAAGTCTCCT & 99 \\
\hline CD133 & TTGTGGCAAATCACCAGGTA & TCAGATCTGTGAACGCCTTG & 162 \\
\hline Nestin & AGCCCTGACCACTCCAGTTTAG & СCCTCTATGGCTGTTTCTITCTCT & 128 \\
\hline OCT4 & ACATCAAAGCTCTGCAGAAAGAACT & CTGAATACCTTCCCAAATAGAACCC & 127 \\
\hline sox2 & GGAAAGTTGGGATCGAACAA & GCGAACCATCTCTGTGGTCT & 145 \\
\hline WNT7B & GTCCTGTACGTGAAGCTCGG & GTACTGGCACTCGTTGATGC & 174 \\
\hline STAT3 & GCCAGAGAGCCAGGAGCA & GGTTCAGCACCTTCACCATT & 174 \\
\hline HPRT1 & GACCAGTCAACAGGGGACAT & CCTGACCAAGGAAAGCAAAG & 132 \\
\hline
\end{tabular}



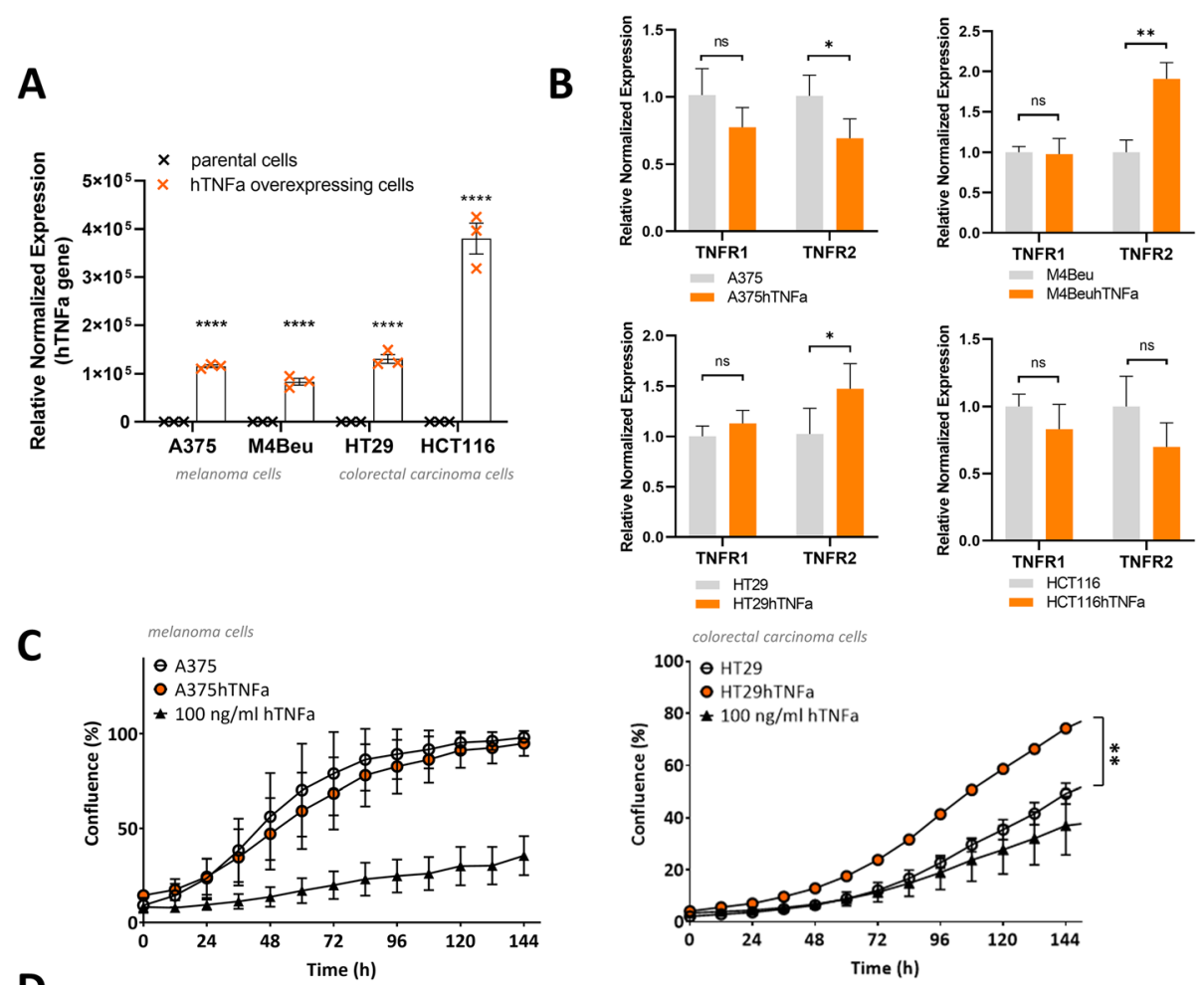

- HT29hTNFa
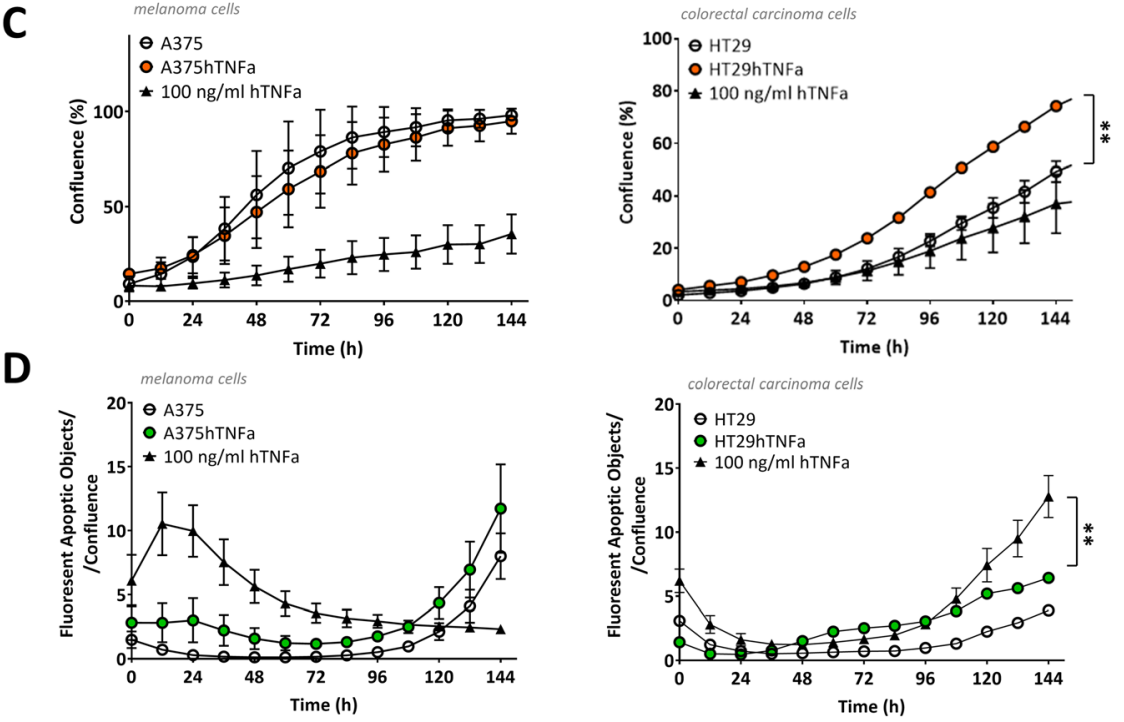

Fig. 1 Extensive mRNA overexpression of TNFa gene in engineered tumor cells does not change significantly the expression of main receptor TNFR1 and did not decrease the ability to proliferate. Cells can overcome slight caspase induction. Reverse transcriptase quantitative PCR for TNFa gene (a) and receptors TNFR1, TNFR2 (b); expression was normalized to the HPRT reference gene, values are means of triplicates or quadruplicates \pm SDs; unpaired t-test was used to statistical analysis. c Continual monitoring of cell proliferation; IncuCyte ZOOM Kinetic Imaging System; means of octaplicates \pm SDs; unpaired t-test was used to statistical analysis of confluence at hour 144. $\mathbf{d}$ Specific apoptosis induction monitoring (caspase 3/7 activation); IncuCyte ZOOM Kinetic Imaging System; means of octaplicates \pm SDs; $100 \mathrm{ng} / \mathrm{ml}$ hTNFa - parental cells treated with recombinant human TNFa protein. A375, M4Beu - melanoma cells, HT29, HCT116 - colorectal carcinoma cells

media during $24 \mathrm{~h}$, while parental cells displayed low or no TNF $\alpha$ protein secretion (Additional file 1). Expression of the crucial receptor TNFR1 was not changed significantly, but the receptor TNFR2 was down- or upregulated in $T N F \alpha$ overexpressing cells with fold change $0.75-2.0$ (Fig. 1b).

The viability and proliferation rate of the cells were not decreased (Fig. 1c), but HT29hTNFa cells displayed an accelerated growth rate, similar to other retrovirally transduced cells. Specific executioner caspase 3/7 activation (Fig. 1d) was not robust. In fast proliferating melanoma cells A375hTNFa, the onset of apoptosis was detected during the first $48 \mathrm{~h}$, in HT29hTNFa carcinoma cells, apoptosis was induced on day 3-4 of cultivation. Engineered tumor cells tolerated extensive $T N F \alpha$ overexpression well and easily overcame partial apoptosis induction.

\section{Autophagy and senescence are induced in malignant melanoma cell lines overexpressing $T N F a$}

Autophagy was monitored by labeling with CYTO-ID dye specific for autophagic vacuoles (Fig. 2). In A375hTNFa cells, an increase of autophagic objects of $17 \%$ was observed on day 3 or 4 of cultivation. Increase of $10 \%$ was detected also in other melanoma cell line M4BeuhTNFa. Colorectal cancer cells displayed no significant increase of autophagic objects (Fig. 2a), but the addition of recombinant human TNF $\alpha$ protein in concentration $100 \mathrm{ng} / \mathrm{ml}$ increased autophagy in HT29 cells (data not shown). 
Significant senescence induction was confirmed in melanoma lines overexpressing $T N F \alpha$ on days 6 and 7 . Characteristic enlarged senescent cells containing blue-dyed precipitates indicating increased senescence-associated $\beta$ galactosidase activity appeared in both melanoma lines A375hTNFa and M4BeuhTNFa (Fig. 3a-b). Senescence induction was observed also in parental melanoma cells treated with recombinant human TNF $\alpha$ protein (Fig. 3a-b). In colorectal carcinoma cells HT29hTNFa and HCT116h TNFa, no differences in the incidence of senescent cells were observed. HCT116 parental cells entered senescence spontaneously and more frequently in comparison to the HT29 cells (Fig. 3c).

\section{Mitochondrial functions of tumor cells are affected by TNFa overexpression}

Because TNF $\alpha$ is manifested as a mild uncoupler of oxidative phosphorylation, the mitochondrial status of engineered tumor cells was monitored. Cellular ATP content was found to be reduced to $75,61,85$ and $67 \%$ in all

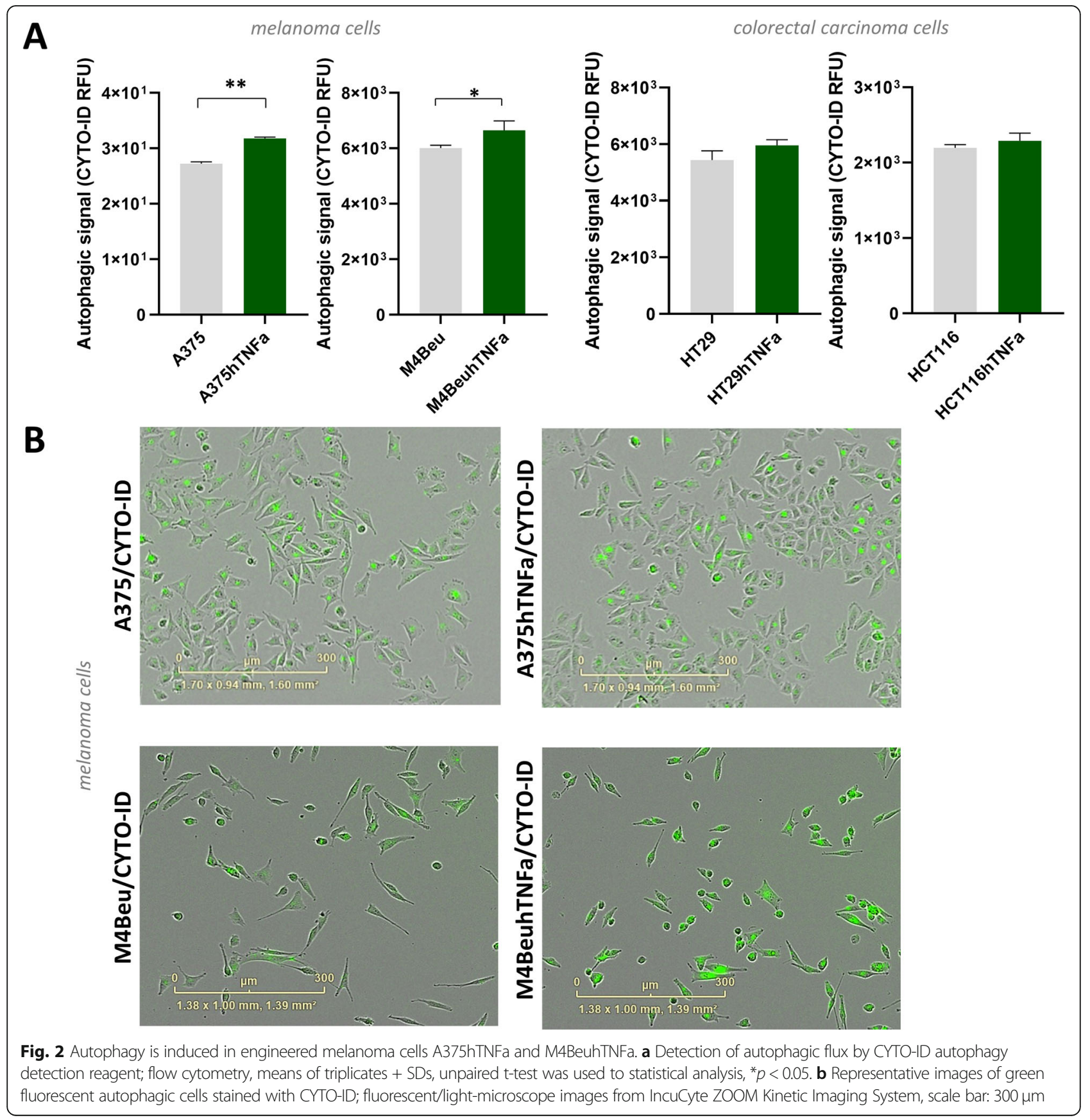




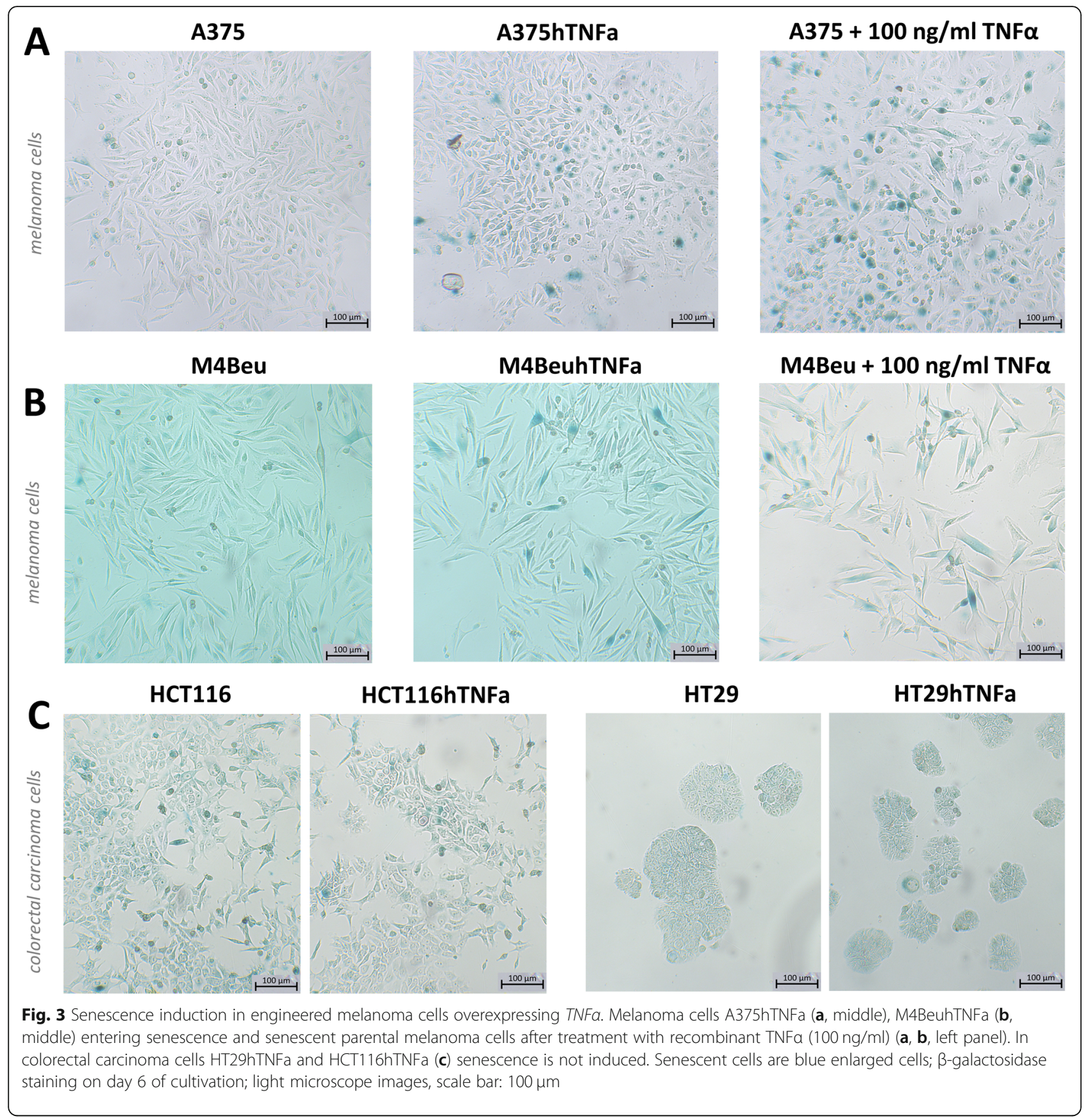

analyzed $T N F \alpha$-overexpressing cell lines (Fig. 4a). Mitochondrial mass stained with MitoTracker DeepRed was significantly reduced in A375hTNFa cells (to 75\%) and in HT29hTNFa cells (to 82\%) compared to parental cells (Fig. 4b). In two other tested cell lines, M4BeuhTNFa and HCT116hTNFa, mitochondrial mass maintained stable. Mitochondrial membrane potential specifically stained with MitoTracker Orange CMT, indicating mitochondrial activity, remained unchanged in engineered cells. Quantitative real-time PCR revealed that the cells also kept constant mitochondrial DNA content under the $T N F \alpha$ overexpression (Additional file 2). Mitochondrial morphology and mitochondrial activity visualized by MitoTracker Orange CMT was not changed significantly, but more condensed and shortened mitochondria with perinuclear localization seemed to 


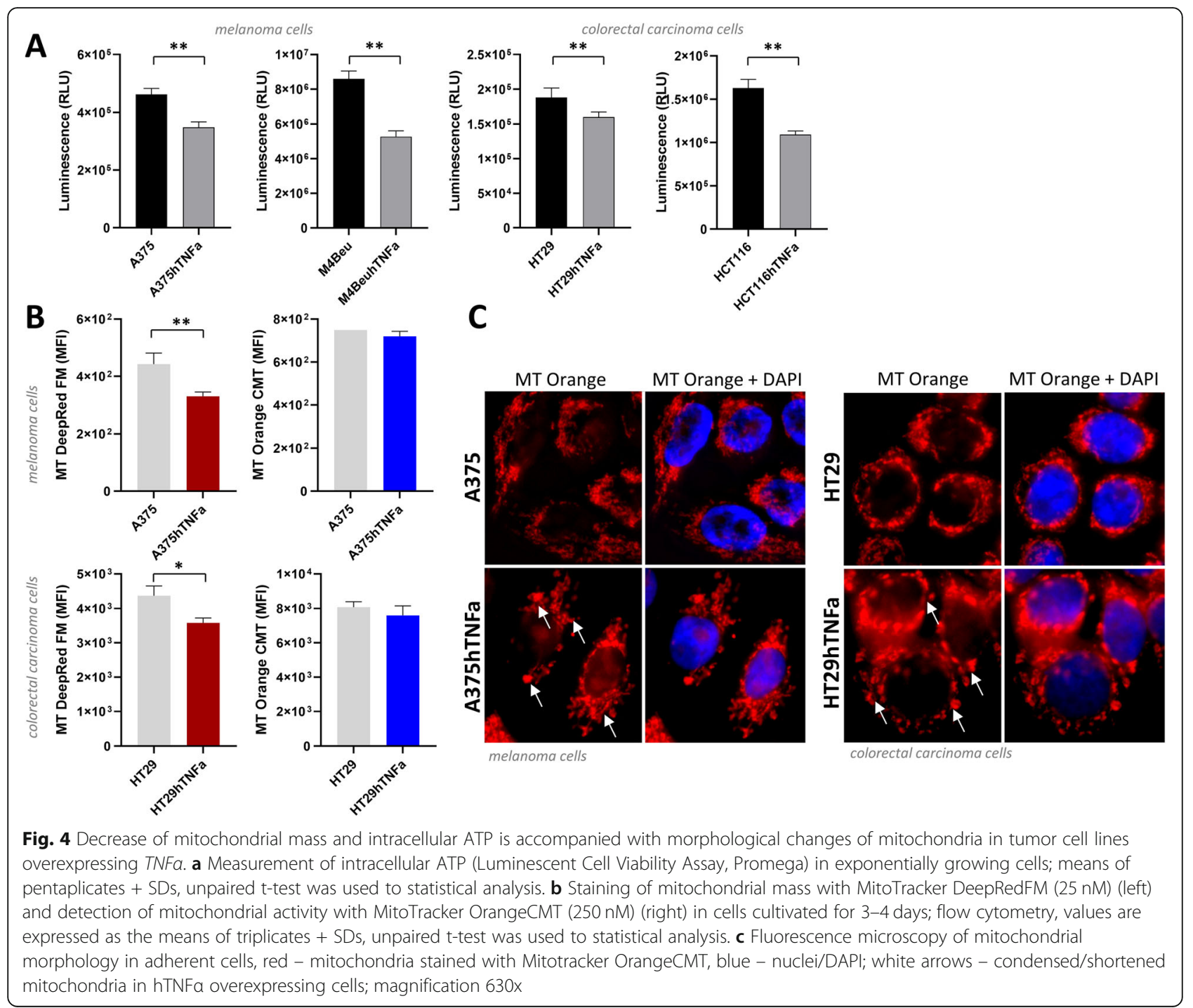

be more abundant in TNF $\alpha$ overexpressing cells. Parental cells displayed more tubular mitochondrial network (Fig. 4c).

\section{Aldehyde dehydrogenase activity is significantly reduced in TNFa overexpressing cells}

High expression of aldehyde dehydrogenase (ALDH) has been reported in both normal and cancer stem cells and ALDH is considered as a marker of stem cells. The proportion of aldehyde dehydrogenase positive cells $(\mathrm{ALDH}+)$ under the overexpression of TNF $\alpha$ in tumor cells was reduced approximately to $50-60 \%$ in comparison to parental cells (Fig. 5) in three engineered cell lines. Melanoma cells M4Beu displayed low innate ALDH activity (8.5\% of ALDH+ cells), increasing to $10.7 \%$ in engineered cells M4BeuhTNFa. Treatment with inhibitor zafirlukast, a compound stabilizing non-functional conformational state of TNFR1 [29], returned the ALDH activity level in engineered melanoma cells A375hTNFa to the level of ALDH activity in parental cells $(83.5 \%$ vs. 85.4\% of ALDH+ cells, unpublished data). In HT29 cells, no significant differences were monitored. Treatment with inhibitor of TNFR1 followed by treatment with recombinant TNF $\alpha(100 \mathrm{ng} / \mathrm{ml})$ did not show significantly increased or decreased levels of ALDH activity in A375 and HT29 cells (unpublished results).

mRNA expression profile shows changes in expression of apoptosis-inducing agent TRAIL and cytokine IL6. CSCslike markers remained unchanged

In engineered melanoma cells A375hTNFa, significant overexpression of inflammatory cytokine IL6 was induced (up to 17 times; Fig. 6a). Overexpression of TNF $\alpha$ in cells HT29hTNFa significantly stimulated expression 


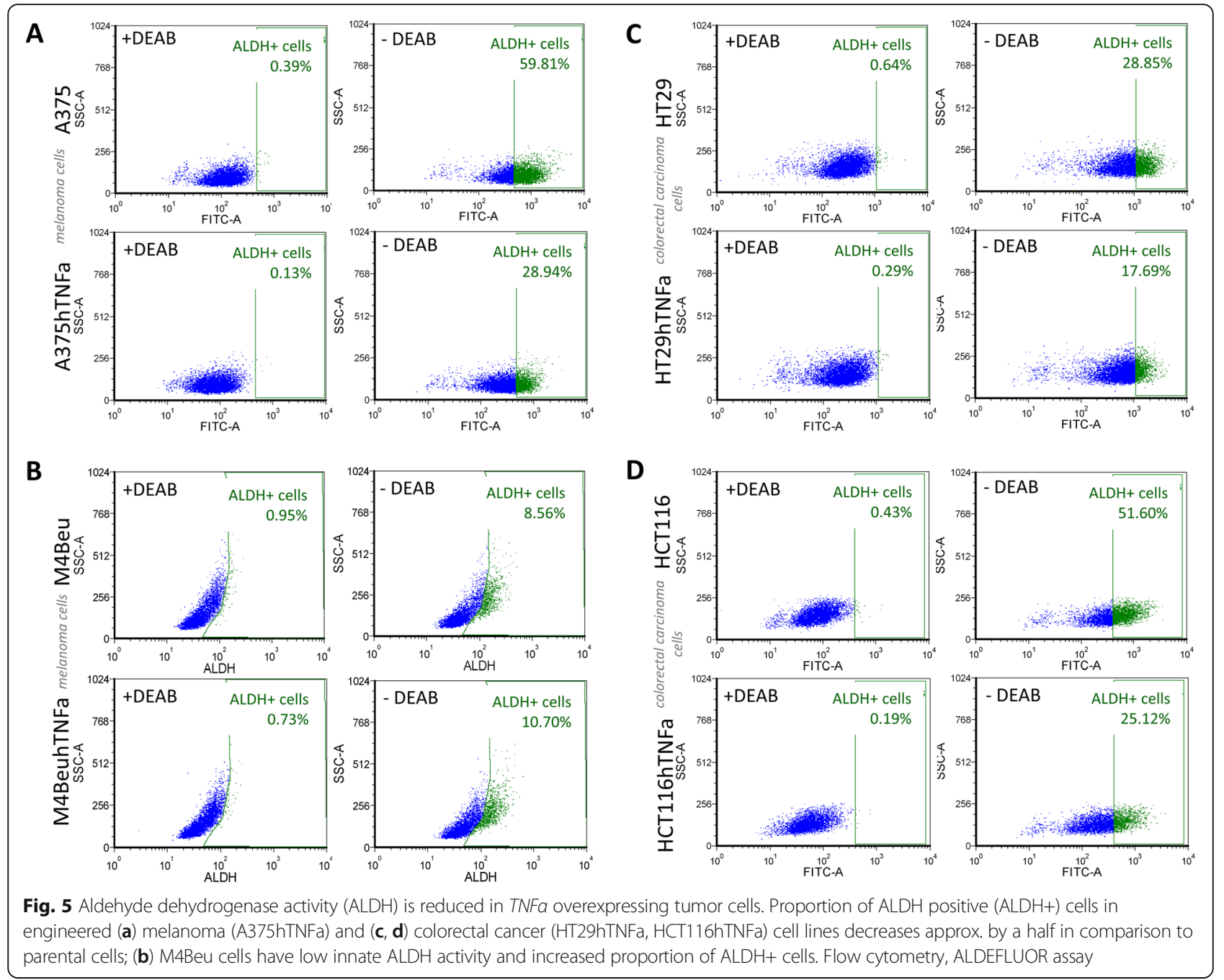

of apoptosis-inducing ligand TRAIL (up to 8 times; Fig. 6b). In A375hTNFa and HT29hTNFa cells, expressions of selected genes encoding stemness markers OCT4, SOX2, NESTIN, and CD133 were not changed significantly in comparison to the parental cells (Fig. 6). No significant changes in expression profile were detected in cells M4BeuhTNFa and HCT116hTNFa (data not shown). Only mRNA for WNT7B gene of WNT- signaling pathway was overexpressed in A375hTNFa cells (Fig. 6a).

Flow cytometric analysis of CSC markers (CD24, CD26, CD44, CD133, CD166, CD271, cMET, EpCAM) did not reveal significant changes in $T N F \alpha$ - engineered cells (Additional file 3). Small divergences were observed, such as a decrease of CD166 positive cells and an increase in CD24 and CD26 in HT29hTNFa carcinoma cells. Insignificant deviations in markers CD271, CD44, and CD166 were noticed in A375hTNFa, while CD133 and c-MET markers remained unchanged.
Subpopulations of CSCs are able to form 3D spheroids. Three of our four tested cell lines overexpressing TNF $\alpha$ (A375, HT29, HCT116) were able to form melanospheres or colonospheres in similar appearance, quantity, and size as their parental counterparts (Additional file 4). However, melanoma cells M4Beu were not able to grow in 3D spheres in given conditions [30].

The specific role of TNF $\alpha$ in stimulation the TRAIL or IL6 gene overexpression was confirmed by exposing cells to TNFR1 inhibitor zafirlukast. Inhibition of TNFR1 by this component resulted in a progressive significant decrease of TRAIL expression in colorectal carcinoma cells HT29hTNFa 2 and $4 \mathrm{~h}$ post-treatment (Additional file 5a). In parental melanoma cells A375, zafirlukast itself, surprisingly, dramatically increased expression of $T N F \alpha$ mRNA (up to 100 times) and also increased IL6 expression (Additional file 5c-e). Its inhibitory effect was observed firstly $4 \mathrm{~h}$ post-treatmentand was less evident in 
A

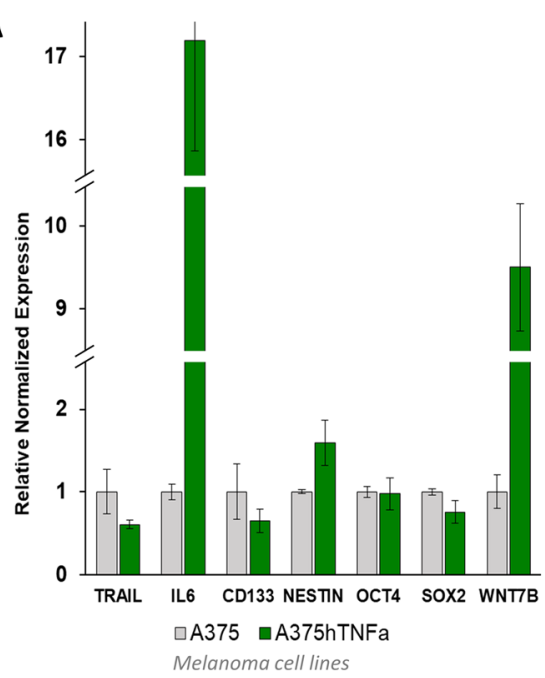

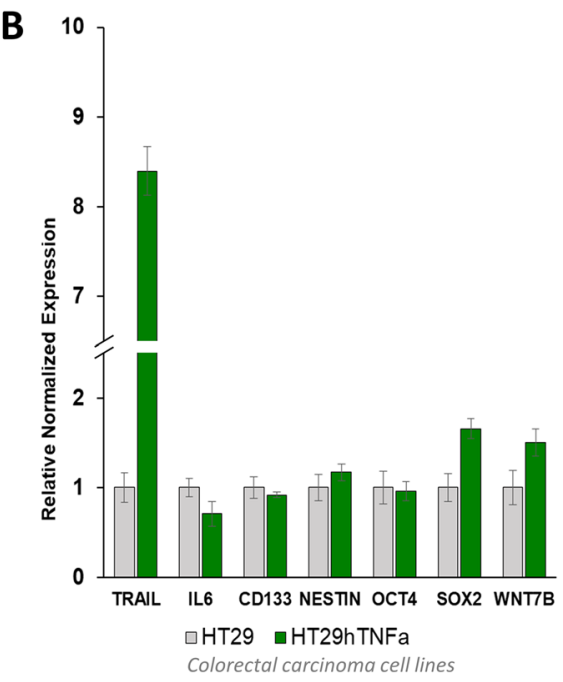

Fig. 6 Expression profile changes in engineered hTNFa tumor cells. a In melanoma cells A375hTNFa, mRNA of inflammatory cytokine IL6 is extensively overexpressed; (b) carcinoma cells HT29hTNFa are stimulated to overexpress TNFa apoptosis-inducing ligand TRAIL mRNA. Expression of pluripotency and stemness markers OCT4, SOX2, NESTIN and marker of cancer stem cells CD133 are not changed significantly; reverse transcriptase quantitative PCR, triplicates \pm SEMs

A375hTNFa melanoma cells in comparison to colorectal carcinoma cells HT29hTNFa.

\section{Discussion}

One of our major findings is that the overexpression of $T N F \alpha$ in engineered colorectal carcinoma and melanoma cell lines is not linked with significant affection of the subpopulation of CSCs in vitro. Monitored CSCs-surface markers, associated with stemness, resistance, tumor progression, adhesion, and invasion, were find to be not significantly up- or downregulated and TNF $\alpha$ makes cells only slightly more positive for these markers (CD166 and CD271 in melanoma; CD24 and CD26 in carcinoma) (Additional file 3). According to works of Storci et al. and Liu et al. $[15,16]$, treatment of tumor cells with TNF $\alpha$ increased CSCs subpopulation in breast carcinoma cell line (i.e. CD44+, ALDH+ cells, and mammosphere counts). Our findings did not show similar changes in melanoma and colorectal carcinoma cells and the mRNA expression of CSCs-related genes (OCT4, SOX2, NANOG, CD133) was not significantly changed. We can also demonstrate unchanged ability to grow in $3 \mathrm{D}$ cultures and form in vitromelanospheres and colonospheres under the TNF $\alpha$ overexpression in vitro. The ability to generate spheres in suspension culture is attributed to CSCs-subpopulation, known also as tumorinitiating cells, which are responsible for tumor formation and relapse. We can conclude, that TNF $\alpha$ overexpression in our cancer cells was not able to hit CSCs subpopulation in vitro and is not responsible for the loss of tumorigenic potential of engineered cells in vivo.
However, we can demonstrate a significant decrease in ALDH activity in vitro. Aldehyde dehydrogenase ALDH is a critical component of the oxidative stress response and detoxification, overexpressed in various tumors, promoting chemoresistance, and considered as an important CSCs marker [31]. We observed a decrease in ALDH activity up to $50 \%$, independently of the fact, that TNFo increases ROS production. This is in contrast to the findings of Moreb et al. [32] and Liu et al. [16], showing increased both ALDH mRNA and ALDH protein activity in human bone marrow cells and malignant cells treated with TNF $\alpha$, respectively. Based on our experiments with TNFR1 inhibitor zafirlukast, we can conclude that ALDH activity is (i) not affected directly by addition of recombinant TNF $\alpha$ protein, but (ii) in engineered cells overexpressing $T N F \alpha$, the ALDH decrease is probably caused indirectly by unknown mechanism. Despite decreased ALDH positivity, flow cytometry measurements, and spheroid formation assay did not indicate affected subpopulation of CSCs. The issue of decreased ALDH activity under the stable overexpression of TNF $\alpha$ needs deeper investigation because there are only a few published studies till today.

Under the TNF $\alpha$ overexpression, the mRNA of two important genes was significantly upregulated: proinflammatory cytokine IL6 in melanoma cells A375hTNFa, and pro-apoptotic ligand TRAIL in carcinoma cells HT29hTNFa. Overexpression of TRAIL gene in carcinoma cells explains the increase of caspase induction in HT29hTNFa in vitro. In melanoma cells, TNF $\alpha$ overexpression accompanied by the secretion of potent cytokine IL6 will be probably able to induce a strong inflammatory 
response in vivo. Since IL6 increases melanoma invasiveness and elevated levels of IL6 are linked with worse prognosis in non-responding patients [33,34], resulting effect of TNF $\alpha$ overexpression can be also adverse.

In our study, engineered malignant melanoma lines A375hTNFa and M4BeuhTNFa have displayed increased autophagy on day 3 , followed by premature senescence on day 6. Both processes might be interconnected [19], following earlier apoptosis induction and deregulation of mitochondrial functions (Fig. 7). These processes can have a positive tumor-suppressive effect. It is known, that TNF $\alpha$ triggers premature senescence in various cell types, such as endothelial, epithelial, and leukemic cells $[35,36]$ and here we can confirm the senescence induction also in malignant melanoma cells. Autophagy activation after TNF $\alpha$ treatment was previously observed in osteoblasts [37]. However, the senescence was not induced in colorectal carcinoma cells HT29hTNFa and HCT116hTNFa suggesting the two different mechanisms of TNF $\alpha$ action in carcinoma cells and in melanoma cells (Fig. 7). Overexpression of IL6 can also represent an explanation for senescence induction in melanoma because IL6 is a known initiator of senescence [38] and an important component of SASP $[39,40]$. On the other hand, significant upregulation of the TRAIL gene was reported also in human MSCs treated with TNFo. These MSCs exerted tumor-suppressive properties on breast cancer xenografts [8].
Different mitochondrial metabolism of cancer cells, known as the Warburg effect, distinguishes tumor cells from normal cells [41] and is considered as possible target of anticancer therapy. We documented altered mitochondrial status of malignant cells under the long term overexpression of TNFa: lowered ATP production and lowered mitochondrial mass. This is in accordance with several studies [24, 25] showing altered mitochondrial metabolism and increased mitochondrial fragmentation in liver cells and adipocytes after TNF $\alpha$ treatment. The mitochondrial membrane potential of engineered $T N F \alpha$ overexpressing cells remained unchanged in our study. Since the level of the mitochondrial mass is decreased in $T N F \alpha$ - tumor cells, we can also speculate, that there can be some increase of mitochondrial activity. Depending on energetic needs and stress stimuli, also mitochondrial morphology is continuously changing. Cancer cells display more shortened mitochondria than normal cells and the fragmentation is also more apparent after stress stimuli [42]. A study of Maeda et al. describes increased mitochondrial fission/fragmentation and release of intact mitochondria from the TNF $\alpha$ - treated human leukemia cells during programmed necrosis (necroptosis) and sterile inflammation [43]. In our TNF $\alpha$ - engineered cells, we have demonstrated similar altered mitochondrial morphology - more rounded and condensed mitochondria and less visible tubular network in comparison to their parental counterpart.

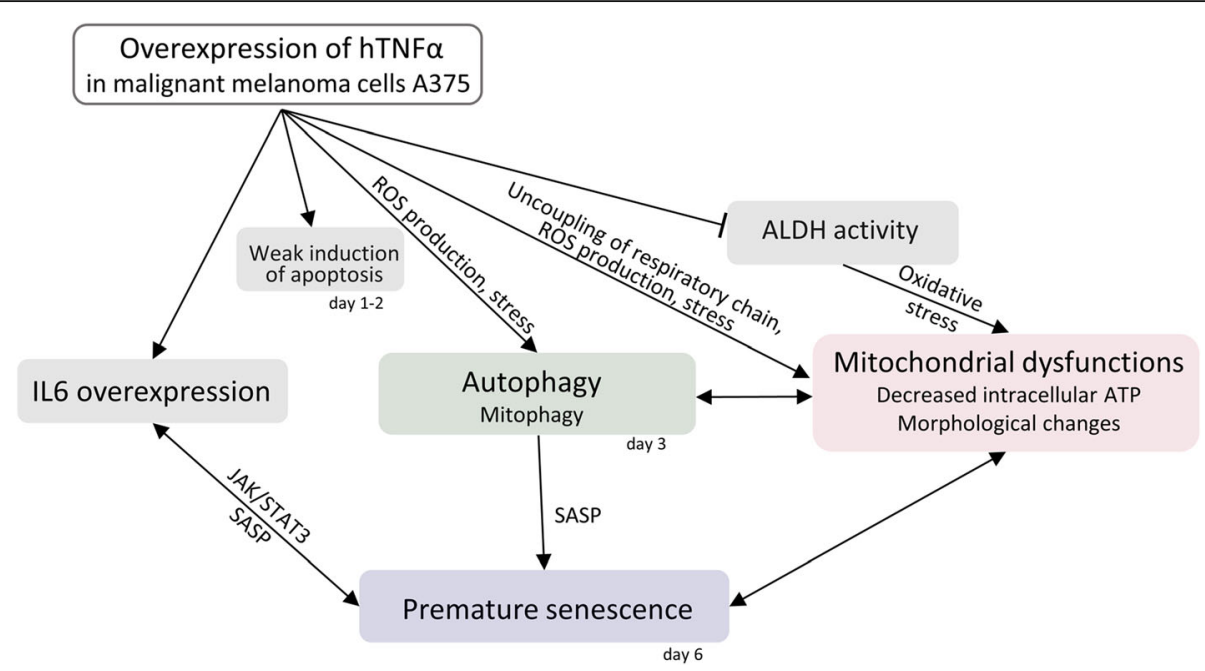

Fig. 7 Possible relationships between TNFa overexpression, apoptosis, autophagy, mitochondrial status and senescence in engineered melanoma cells A375hTNFa. Overexpression of TNFa induces weak apoptosis activation on day 1-2 and most of the cells enter survival/inflammation pathway. TNFa induces ROS production, stress and fragmentation of mitochondria. It is manifested as a mild uncoupler and causes decreased levels of intracellular ATP. Autophagy, and probably also mitophagy, are activated on day 3 and can bring mitochondrial dysfunctions too. And mitochondrial dysfunctions can be a cause of mitophagy. ALDH activity is reduced to $50 \%$ and probably cannot ensure complete detoxification of products of oxidative stress. Overexpression of TNFa induces significant overexpression of IL6, known inducer of JAK/STAT3 signalling pathway, inducer of senescence and component of SASP. Finally, autophagy, IL6, mitochondrial dysfunctions and oxidative stress caused by TNFa lead to premature senescence in malignant melanoma cells A375hTNFa. IL6 - interleukin 6, ALDH - aldehyde dehydrogenase, ROS - reactive oxygen species, SASP - senescence associated phenotype, JAKJSTAT3 - signalling pathway 


\section{Conclusions}

Our work reports the impact of TNF $\alpha$ on cancer cells of different origin - non-epithelial malignant melanoma cells of neural crest origin and colorectal carcinoma cell lines of epithelial origin. TNF $\alpha$ acts differently in these cells, confirming its pluripotency and indicating two possible ways of action. In melanoma cells, inflammation/ survival pathway is supported by IL6 overexpression, and activation of autophagy followed by premature senescence is initiated. Deregulation of mitochondria and changes in mitochondrial morphology were noticed in both cancer cell types. Carcinoma cells are stimulated to overexpress pro-apoptotic gene TRAIL and they avoid to activate other inflammatory mediators. But the final effect of TNF $\alpha$ is mild in vitro, limited by the availability of its receptors TNFR1 and TNFR2 and presumably predominant activation of pro-survival pathway NF-kB. Despite such high overexpression of TNF $\alpha$ protein in engineered tumor cells, the subpopulation of CSCs responsible for tumor growth initiation remained unaffected, not increased or decreased, and is not directly linked with the loss of tumorigenic potential.

\section{Abbreviations}

ALDH: Aldehyde dehydrogenase; ATP: Adenosine triphosphate;

IL6: Interleukin 6; TNFa: Tumor necrosis factor a; TNFR1/TNFR2: TNF receptor 1/TNF receptor 2; TRAIL: TNF-related apoptosis-inducing ligand;

MSC: Mesenchymal stromal cells; CSCs: Cancer stem-like cells;

SASP: Senescence-related secretory phenotype; ROS: Reactive oxygen species

\section{Supplementary Information}

The online version contains supplementary material available at https://doi. org/10.1186/s12885-021-08237-1.

Additional file 1: Figure S1. Engineered melanoma (A375hTNFa, M4BeuhTNFa) and colorectal carcinoma cells (HT29hTNFa, HCT116hTNFa) secrete high levels of TNFa protein. ELISA quantification of TNFa protein in conditioned media harvested from cells reaching $90-100 \%$ confluence during 24 h; means of triplicates + SDs.

Additional file 2: Figure S2. Mitochondrial DNA content is not changed in TNFa overexpressing melanoma (a) and colorectal carcinoma cells (b). Mitochondrial DNA content (mtDNA) represented by gene for $16 \mathrm{~S}$ rRNA was normalized to a nuclear DNA (nDNA) represented by $\beta 2$ microglobulin gene; quantitative PCR, triplicates \pm SDs.

Additional file 3: Figure S3. Cancer stem cell-related markers remained unchanged under the overexpression of TNFa gene in melanoma (a) and colorectal carcinoma cells (b, c). Flow cytometry analysis; cells overexpressing TNFa (red line) and parental cells (black line) stained with specific anti-human antibodies against CSCs markers; isotype control antibodies as staining controls of TNFa overexpressing cells (blue line) and parental cells (grey line).

Additional file 4: Figure S4. Spheroid formation ability is not affected under the TNFa overexpression. Spheroids of melanoma cells A375 (melanospheres) were grown in passage 0 for 4 days; spheroids of colorectal carcinoma cells HT29 and HCT116 (colonospheres) were grown in passage 1 for 3 days. Colonospheres later quickly fused together into big spheres with length of more than $600 \mu \mathrm{m}$. (a) Lengths of spheres; bars represent medians, $n=20-30$, Mann-Whitney test; (b) representative light microscope images, scale bar: $100 \mu \mathrm{m}$.

Additional file 5: Figure S5. Inhibitor of TNFR1 receptor zafirlukast (ZAF) inhibits (a) TRAIL gene overexpression in engineered colorectal carcinoma cells HT29hTNFa and (d) IL6 gene expression in malignant melanoma cells A375hTNFa (highlighted with red line). (e) Zafirlukast itself also significantly increases TNFa gene expression in parental cells A375, so its inhibitory effect on IL6 overexpression (d) is evident firstly after $4 \mathrm{~h}$ post-treatment. (a, c, d) Overexpression of TRAIL and IL6 confirmed in TNFa overexpressing cells and in control cells treated with recombinant TNFa $(100 \mathrm{ng} / \mathrm{ml})$. Cells were treated with zafirlukast $(100 \mu \mathrm{M})$ for $1 \mathrm{~h}$ at $37^{\circ} \mathrm{C}$; recombinant TNFa $(100 \mathrm{ng} / \mathrm{ml})$ was then added to the control samples for 2 and $4 \mathrm{~h}$ ( $2 \mathrm{~h}, 4 \mathrm{~h}$ ) post- zafirlukast treatment and then all cells were immediately harvested for reverse quantitative PCR for TRAIL, IL6 and TNFa gene. Expression normalized to HPRT1 reference gene; values are mean of triplicates \pm SDs; unpaired t-test was used to statistical analysis. Pictures (c) and (d) represent independent experiments.

\section{Acknowledgments}

We thank Dr. Jana Jakubikova for technical assistance with flow cytometry, Dr. Bozena Smolkova for help with statistic evaluation, Maria Dubrovcakova and Alena Linekova for excellent technical assistance. We thank Dr. Sona Ciernikova for carefully reading the manuscript.

\section{Authors' contributions}

ST: Conceptualization, Methodology, Formal analysis, Visualization, Investigation, Writing - Original Draft, Writing - Review \& Editing, Supervision; MM: Methodology, Formal analysis, Visualization, Writing - Review \& Editing, Supervision; BS: Methodology, Writing - Review \& Editing; W: Methodology, Formal analysis. The authors read and approved the final manuscript.

\section{Funding}

This work was supported by VEGA grants no. 02/178/17, 02/0050/19; by Ministry of Health of the Slovak Republic under the project registration number 2019/60-BMCSAV-4, EU Horizon 2020 Research and Innovation programme under grant agreement No 857381 (VISION), by UVP BIOMED - project ITMS 26240220087 and by Slovak Cancer Research Foundation RFL2009 and RFL2012 programs. The funding did not affect the design of the study, collection, analysis or interpretation of data or preparation of the manuscript.

Availability of data and materials

Datasets of this study are available through the corresponding author on reasonable request.

\section{Declarations}

Ethics approval and consent to participate

No cell lines used in this manuscript require ethics approval for their use.

Consent for publication

Not applicable.

\section{Competing interests}

The authors declare that they have no competing interests.

\section{Author details}

${ }^{1}$ Cancer Research Institute, Biomedical Research Center of Slovak Academy of Sciences, Dubravska cesta 9, 84505 Bratislava, Slovakia. ${ }^{2}$ Department of Genetics, Faculty of Natural Sciences, Comenius University, Mlynská dolina, Ilkovicova 6, 84215 Bratislava, Slovakia.

Received: 6 September 2020 Accepted: 22 April 2021

Published online: 06 May 2021

\section{References}

1. Balkwill F. Tumour necrosis factor and cancer. Nat Rev Cancer. 2009;9(5): 361-71. https://doi.org/10.1038/nrc2628.

2. Lebrec H, Ponce R, Preston BD, Iles J, Born TL, Hooper M. Review Tumor necrosis factor, tumor necrosis factor inhibition, and cancer risk. Curr Med Res Opin Cit Curr Med Res Opin. 2015;31(3):557-74. https://doi.org/10.1185/ 03007995.2015.1011778.

3. Drutskaya MS, Efimov GA, Kruglov AA, Kuprash DV, Nedospasov SA. Tumor necrosis factor, lymphotoxin and cancer. IUBMB Life. 2010;62(4):283-9. https://doi.org/10.1002/iub.309. 
4. Hock H, Dorsch M, Kunzendorf U, Qin Z, Diamantstein T, Blankenstein T. Mechanisms of rejection induced by tumor cell-targeted gene transfer of interleukin 2, interleukin 4, interleukin 7, tumor necrosis factor, or interferon gamma. Proc Natl Acad Sci U S A. 1993;90(7):2774-8. https://doi.org/10.1 073/pnas.90.7.2774.

5. Al-Zoubi M, Salem AF, Martinez-Outschoorn UE, Whitaker-Menezes D, Lamb R, Hulit J, et al. Creating a tumor-resistant microenvironment cell-mediated delivery of TNFa completely prevents breast cancer tumor formation in vivo. Cell Cycle. 2013;12(3):480-90. https://doi.org/10.4161/cc.23370.

6. Blankenstein T, Qin ZH, Uberla K, Müller W, Rosen H, Volk HD, et al. Tumor suppression after tumor cell-targeted tumor necrosis factor alpha gene transfer. J Exp Med. 1991;173(5):1047-52. https://doi.org/10.1084/jem.173.5.1047.

7. Vanhaesebroeck B, Marcel M, Roy F Van, Grooten J, Fiers W. Expression of the Tumor Necrosis Factor Gene in Tumor Cells Correlates with Reduced Tumorigenicity and Reduced Invasiveness in Vivo. Cancer Res. 1991;51(8): 2229-38.

8. Lee RH, Yoon N, Reneau JC, Prockop DJ. Preactivation of human MSCs with TNF-a enhances tumor-suppressive activity. Cell Stem Cell. 2012;11(6):82535. https://doi.org/10.1016/j.stem.2012.10.001.

9. Tyciakova S, Matuskova M, Bohovic R, Polakova K, Toro L, Skolekova S, et al. Genetically engineered mesenchymal stromal cells producing TNFa have tumour suppressing effect on human melanoma xenograft. J Gene Med. 2015;17(1-2):54-67. https://doi.org/10.1002/jgm.2823.

10. Tyciakova S, Matuskova M, Bohovic R, Kucerova L. Mesenchymal stromal cells producing TNFa lack inhibitory effect against A375 experimental lung metastases. Neoplasma. 2017;64(2):222-7. https://doi.org/10.4149/neo_2017_208.

11. Reya T, Morrison SJ, Clarke MF, Weissman IL. Stem cells, cancer, and cancer stem cells. Nature. 2001;414(6859):105-11. https://doi.org/10.1038/35102167.

12. Agliano A, Calvo A, Box C. The challenge of targeting cancer stem cells to halt metastasis. Semin Cancer Biol. 2017;44:25-42. https://doi.org/10.1016/j. semcancer.2017.03.003.

13. Lee $\mathrm{SH}$, Hong HS, Liu ZX, Kim RH, Kang MK, Park NH, et al. TNFa enhances cancer stem cell-like phenotype via notch-Hes1 activation in oral squamous cell carcinoma cells. Biochem Biophys Res Commun. 2012;424(1):58-64. https://doi.org/10.1016/j.bbrc.2012.06.065.

14. Kali A, Ostapchuk YO, Belyaev NN. TNFa and TGFB-1 synergistically increase the cancer stem cell properties of MiaPaCa-2 cells. Oncol Lett. 2017;14(4): 4647-58. https://doi.org/10.3892/ol.2017.6810.

15. Storci G, Sansone P, Mari S, D'Uva G, Tavolari S, Guarnieri T, et al. TNFalpha up-regulates SLUG via the NF-kappaB/HIF1alpha axis, which imparts breast cancer cells with a stem cell-like phenotype. J Cell Physiol. 2010;225(3):68291. https://doi.org/10.1002/jcp.22264.

16. Liu W, Lu X, Shi P, Yang G, Zhou Z, Li W, et al. TNF-a increases breast cancer stem-like cells through up-regulating TAZ expression via the non-canonical NF-kB pathway. Sci Rep. 2020;10:1-11.

17. Asiedu MK, Ingle JN, Behrens MD, Radisky DC, Knutson KL. TGFß/TNFamediated epithelial-mesenchymal transition generates breast cancer stem cells with a claudin-low phenotype. Cancer Res. 2011;71(13):4707-19. https://doi.org/10.1158/0008-5472.CAN-10-4554.

18. Baker S, Ali I, Silins I, Pyysalo S, Guo Y, Högberg J, et al. Cancer hallmarks analytics tool (CHAT): a text mining approach to organize and evaluate scientific literature on cancer. Bioinformatics. 2017;33(24):3973-81. https:// doi.org/10.1093/bioinformatics/btx454.

19. Rajendran P, Alzahrani AM, Hanieh HN, Kumar SA, Ben Ammar R, Rengarajan T, et al. Autophagy and senescence: a new insight in selected human diseases. J Cell Physiol. 2019;234(12):21485-92. https://doi.org/10.1002/jcp.28895.

20. White E. Deconvoluting the context-dependent role for autophagy in cancer. Nat Rev Cancer. 2012;12(6):401-10. https://doi.org/10.1038/nrc3262.

21. Singh SS, Vats S, Chia AYQ, Tan TZ, Deng S, Ong MS, et al. Dual role of autophagy in hallmarks of cancer. Oncogene. 2018;37(9):1142-58. https:// doi.org/10.1038/s41388-017-0046-6.

22. Falandry C, Bonnefoy M, Freyer G, Gilson E. Biology of cancer and aging: a complex association with cellular senescence. J Clin Oncol. 2014;32(24): 2604-10. https://doi.org/10.1200/JCO.2014.55.1432.

23. Nikoletopoulou V, Markaki M, Palikaras K, Tavernarakis N. Crosstalk between apoptosis, necrosis and autophagy. Biochim Biophys Acta - Mol Cell Res. 1833;2013:3448-59.

24. Hahn WS, Kuzmicic J, Burrill JS, Donoghue MA, Foncea R, Jensen MD, et al. Proinflammatory cytokines differentially regulate adipocyte mitochondrial metabolism, oxidative stress, and dynamics. AJP
Endocrinol Metab. 2014;306(9):E1033-45. https://doi.org/10.1152/ajpendo. 00422.2013.

25. Kastl L, Sauer SW, Ruppert T, Beissbarth T, Becker MS, Süss D, et al. TNF-a mediates mitochondrial uncoupling and enhances ROS-dependent cell migration via NF-kB activation in liver cells. FEBS Lett. 2014;588(1):175-83. https://doi.org/10.1016/j.febslet.2013.11.033.

26. Sotgia F, Ozsvari B, Fiorillo M, De EM, Bonuccelli G, Lisanti MP, et al. A mitochondrial based oncology platform for targeting cancer stem cells ( CSCs ): MITO-ONC-RX. Cell Cycle. 2018;17(17):2091-100. https://doi.org/10.1 080/15384101.2018.1515551.

27. Vega-Naredo I, Loureiro R, Mesquita KA, Barbosa IA, Tavares LC, Branco AF, et al. Mitochondrial metabolism directs stemness and differentiation in P19 embryonal carcinoma stem cells. Cell Death Differ. 2014;21(10):1560-74. https://doi.org/10.1038/cdd.2014.66.

28. Venegas V, Wang J, Dimmock D, Wong L-J. Real-Time Quantitative PCR Analysis of Mitochondrial DNA Content. In: Current Protocols in Human Genetics. 2011; Chapter 19:Unit 19.7.

29. Weinelt N, Karathanasis C, Smith S, Medler J, Malkusch S, Fulda S, et al. Quantitative single-molecule imaging of TNFR1 reveals zafirlukast as antagonist of TNFR1 clustering and TNFa-induced NF-kB signaling. J Leukoc Biol. 2021;109(2):363-71. https://doi.org/10.1002/ JLB.2AB0420-572RR

30. Kucerova L, Skolekova S, Matuskova M, Bohac M, Kozovska Z. Altered features and increased chemosensitivity of human breast cancer cells mediated by adipose tissue-derived mesenchymal stromal cells. BMC Cancer. 2013;13(1):535. https://doi.org/10.1186/1471-2407-13-535.

31. Kozovska Z, Gabrisova V, Kucerova L. Colon cancer: Cancer stem cells markers, drug resistance and treatment. Biomed Pharmacother. 2014;68(8): 911-6. https://doi.org/10.1016/j.biopha.2014.10.019.

32. Moreb JS, Turner C, Sreerama L, Zucali JR, Sladek NE, Schweder M. Interleukin-1 and tumor necrosis factor alpha induce class 1 aldehyde dehydrogenase mRNA and protein in bone marrow cells. Leuk Lymphoma. 1995;20(1-2):77-84. https://doi.org/10.3109/10428199509054756.

33. Hoejberg L, Bastholt L, Schmidt H. Interleukin-6 and melanoma. Melanoma Res. 2012;22(5):327-33. https://doi.org/10.1097/CMR.0b013e3283543d72.

34. Rossi S, Cordella M, Tabolacci C, Nassa G, D'Arcangelo D, Senatore C, et al. TNF-alpha and metalloproteases as key players in melanoma cells aggressiveness. J Exp Clin Cancer Res. 2018;37:1-17.

35. Schosserer M, Grillari J, Breitenbach M. The dual role of cellular senescence in developing tumors and their response to cancer therapy. Front Oncol. 2017;7:278. https://doi.org/10.3389/fonc.2017.00278.

36. Hinds P, Pietruska J. Senescence and tumor suppression. F1000Research. 2017;6:2121.

37. Zheng L, Wang W, Ni J, Mao X, Song D, Liu T, et al. Role of autophagy in tumor necrosis factor-a-induced apoptosis of osteoblast cells. J Investig Med. 2017;65(6):1014-20. https://doi.org/10.1136/jim-2017-000426.

38. Kojima H, Inoue T, Kunimoto H, Nakajima K. IL-6-STAT3 signaling and premature senescence. JAKSTAT. 2013;2(4):e25763. https:/doi.org/10.4161/jkst.25763.

39. Mosteiro L, Pantoja C, de Martino A, Serrano M. Senescence promotes in vivo reprogramming through p16 INK4a and IL-6. Aging Cell. 2018;17(2): e12711. https://doi.org/10.1111/acel.12711.

40. Ortiz-Montero P, Londoño-Vallejo A, Vernot JP. Senescence-associated IL-6 and IL-8 cytokines induce a self- and cross-reinforced senescence/ inflammatory milieu strengthening tumorigenic capabilities in the MCF-7 breast cancer cell line. Cell Commun Signal. 2017;15(1):17. https://doi.org/1 0.1186/s12964-017-0172-3.

41. Gogvadze V, Zhivotovsky B, Orrenius S. The Warburg effect and mitochondrial stability in cancer cells. Mol Asp Med. 2010;31(1):60-74. https://doi.org/10.1016/j.mam.2009.12.004.

42. Youle RJ, Van Der Bliek AM. Mitochondrial fission, fusion, and stress. Science. 2012;337(6098):1062-5. https://doi.org/10.1126/science.1219855.

43. Maeda A, Fadeel B. Mitochondria released by cells undergoing TNF-ainduced necroptosis act as danger signals. Cell Death Dis. 2014;5(7):e1312. https://doi.org/10.1038/cddis.2014.277.

\section{Publisher's Note}

Springer Nature remains neutral with regard to jurisdictional claims in published maps and institutional affiliations. 